\title{
Single-stage septation of a univentricular heart: 26 years later
}

\author{
Eva Maria Delmo Walter, MD, PhD, and Roland Hetzer, MD, PhD, Berlin, Germany
}

Septation of a single ventricle into 2 functioning ventricles is a reasonable alternative to a Fontan operation. However, early experience with septation included unacceptable morbidity and mortality. ${ }^{1,2}$ Possible risk factors for poor outcome included random selection of patients, the necessity of a ventriculotomy for the surgical approach, and loose patch placement resulting in inflow or outflow obstruction. $^{3-5}$

\section{CASE REPORT}

A boy aged 4.5 years, weighing $14 \mathrm{~kg}$, presented with exertion-related dyspnea. A chest roentgenogram showed a borderline-sized heart with dimensions similar to those found in L-malposition of the great arteries. Echocardiography and cardiac catheterization confirmed univentricular heart with 2 atrioventricular valves, both arising from a morphologically left ventricle, and a pulmonary stenosis. The right ventricle was rudimentary, and the aorta and pulmonary artery were in L-malposition.

\section{Surgical Technique}

Under cardiopulmonary bypass, the right atrium was opened with a hook-shaped incision, and the intracardiac morphology was inspected. As expected, advancing out from the right atrium led through a morphologic tricuspid valve, in the presence of an intact atrial septum, into a common ventricle, without any residual septum nor apical muscular rim, of which the right part was trabecularized like the right ventricle. Below the commissure between the anterior and septal tricuspid leaflet, direct access to the pulmonary artery was possible; the artery, with its valve, was in dorsal position, and there was fibrous continuity between the artery and the tricuspid valve.

The pulmonary artery was opened longitudinally, and the valve was bicuspid and wide open. There was clearly no significant pulmonary stenosis, as a 15-mm Hegar (Aesculap AG, Tuttlingen, Germany) dilator could be passed through easily. The aorta arose from a long outflow tract that ran

\footnotetext{
From the Department of Cardiovascular and Thoracic Surgery, Deutsches Herzzentrum Berlin, Berlin, Germany.

Disclosures: Authors have nothing to disclose with regard to commercial support.

Received for publication Dec 1, 2014; accepted for publication Dec 7, 2014; available ahead of print Jan 23, 2015.

Address for reprints: Eva Maria Delmo Walter, MD, PhD, Deutsches Herzzentrum Berlin, Augustenburger Platz 1, 13353 Berlin, Germany (E-mail: delmo-walter@ dhzb.de).

J Thorac Cardiovasc Surg 2015;149:e63-5

$0022-5223 / \$ 36.00$

Copyright (C) 2015 by The American Association for Thoracic Surgery

http://dx.doi.org/10.1016/j.jtcvs.2014.12.018
}

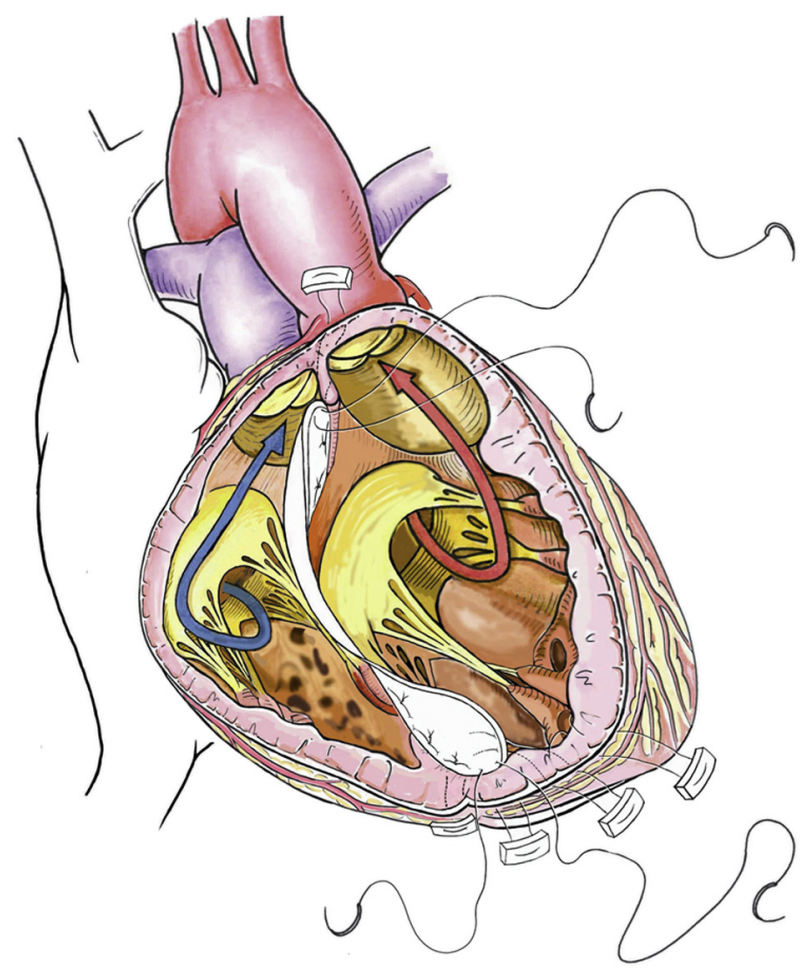

FIGURE 1. Septation procedure: A 20-mm Weavenit patch, geometrically fashioned to an exact fit, was sutured in an interrupted fashion with 4-0 polypropylene, starting at the apex between the papillary muscles of the mitral valve and the tricuspid valve, and continuing along the fusion lines between these valves, avoiding the course of the right coronary artery, to create 2 ventricles and separate them in such a way that the bigger section would be the left ventricle.

far from the mitral valve in anterior and left position and was not stenosed. The intraventricular anatomy was assessed through the right atrioventricular valve; the location of the papillary muscles and the epicardial distribution of the coronary arteries were identified. At that point, the decision was made to perform septation of the singular ventricle.

A 20-mm Weavenit patch (Impra, Inc, Tempe, Ariz), cut to size, was sewn into the ventricle in an interrupted fashion, applying a large number of sutures (20) of 40 polypropylene with Teflon pledgets. Suturing started at the apex between the papillary muscles of the mitral valve and the tricuspid valve and continued along the fusion lines between these valves all the way to the left margin of the pulmonary annulus and the margins of the trabeculated area (right ventricle), and inferiorly to the smoothwalled section (left ventricle). Thus, 2 ventricles were created and separated in such a way that the larger section 

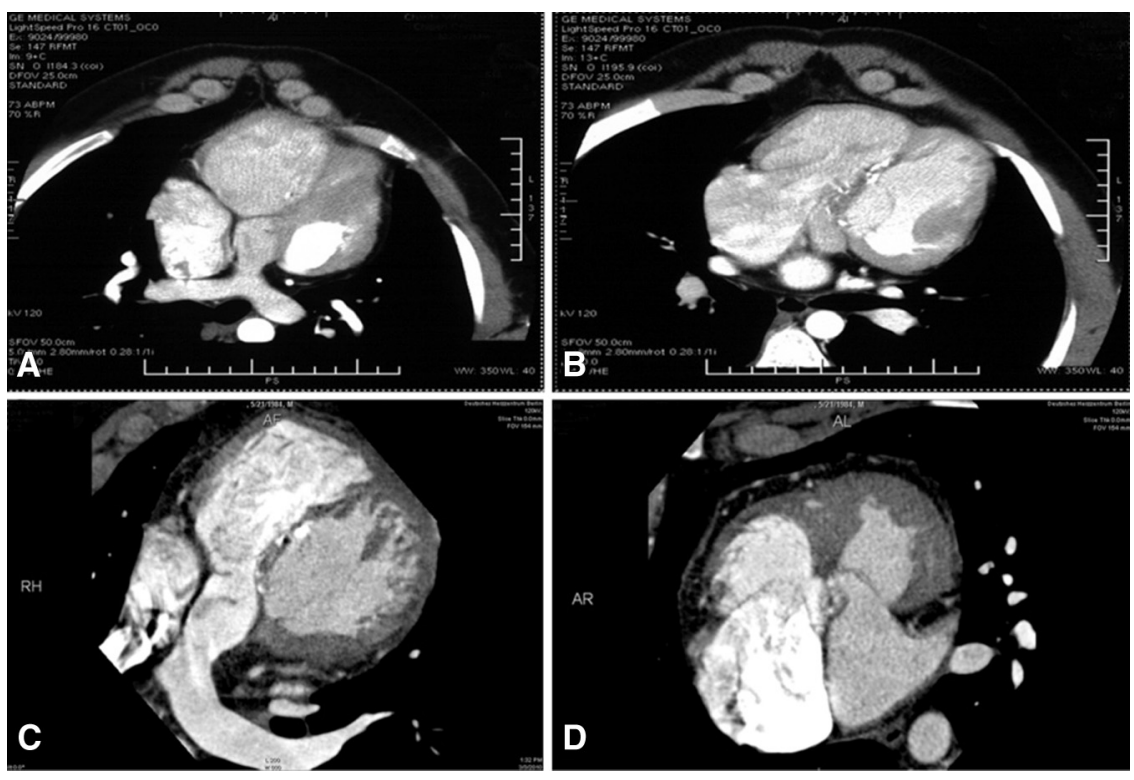

FIGURE 2. Computed cardiac tomography 15 years ( $A$ and $B$ ) and 20 years (C and D) after single-stage septation of a univentricular heart. A and C, Shortaxis view showing 2 normal-sized, well-developed ventricles septated by a prosthetic patch. B and D, Long-axis view showing the fixed septation patch well attached to the endocardium.

would be the left ventricle (Figure 1). Precautions were taken to avoid the right coronary artery when sutures from outside the heart were passed through the myocardium and tied.

Postoperative echocardiography showed good biventricular contractility and normal-sized atria. Catheterization showed a very minimal leak in the apex of the newly created wide interventricular septum, low right ventricle pressure, and a mild pulmonary stenosis. Right and left ventricular outflow were unobstructed. However, at the end of the fifth postoperative year, the patient became easily fatigued, sweated excessively, and developed exertion-related dyspnea. Echocardiography and cardiac catheterization showed progression of the tricuspid valve incompetence, a pulmonary stenosis-producing right ventricle pressure of $65 \mathrm{~mm} \mathrm{Hg}$, and 2 small hemodynamically insignificant ventricular septal defects.

Surgical correction of these findings was deemed necessary. The right atrium was opened with a hook-shaped incision, and the pulmonary artery posterior to the aorta was opened longitudinally. The bicuspid pulmonary valve was wide open, with delicate, mobile leaflets, and was definitely not stenosed. In the subvalvular position was the upper margin of the septation patch, which there formed a small rim; opposite to it was the right-sided atrioventricular valve that was sufficiently wide. The right-sided atrioventricular valve showed ring dilatation and anterior leaflet prolapse. The septation patch was fixed, well integrated, and covered with neo-intima. The previously described ventricular septal defects could not be located and identified; hence, they were presumed to be hidden deep within the apically directed trabecular networks and were not sought further.

Probing the pulmonary artery from the right ventricle showed a wide opening of the pulmonary valve that could not have produced a hemodynamically significant stenosis. It was presumed that the subvalvular stenosis could have been associated with the proximity and contact of the tricuspid valve and the septation patch. Elimination of the subvalvular gradients would have entailed an extensive operation, eg, interposition of a conduit between the right ventricle and the pulmonary artery, which can damage the septation patch, which otherwise was functioning very well. Given the good cardiac function, and the nature of the child's overall condition, this extensive procedure was considered unjustified.

After this assessment, tricuspid valve annuloplasty was performed. Through a limited atrial septal incision, the mitral valve was determined to have thickened leaflets, but it was otherwise competent. Echocardiography showed good ventricular contractility and minimal incompetence of the atrioventricular valves.

Computed cardiac tomography 21 years later revealed an adequately placed and fixed septation patch, equal growth of the 2 ventricles to normal sizes, and absence of the previously described ventricular septal defects without any other morphologic or anatomic cardiac abnormalities (Figure 2, $A-D$ ). Presently, the patient is the father of a 3-year old boy and employed in the hotel business. 
The authors thank Yuguo Weng for providing the graphics, and Anne Gale, medical editor, for assistance with this article.

\section{References}

1. Feldt RH, Mair DD, Danielson GK, Wallace RB, McGoon DC. Current status of the septation procedure for single ventricular hearts. J Thorac Cardiovasc Surg. 1981;82:93-7.

2. Franklin RCG, Spiegelhalter DJ, Filho RR, Macartney FJ, Anderson RH, Rigby ML, et al. Double-inlet ventricle presenting in infancy. III. Outcome and Potential for definitive repair. J Thorac Cardiovasc Surg. 1991;101: 924-34.

3. Doty DB, Schieken RM, Lauer RM. Septation of the single ventricle heart, transatrial approach. J Thorac Cardiovasc Surg. 1979;78:423-30.

4. Margossian RE, Solowiejczyk D, Bourton F, Apfel H, Gersony W, Hordof AM, et al. Septation of the single ventricle: revisited. J Thorac Cardiovasc Surg. 2002;124:442-7.

5. Ebert PA. Staged partitioning of single ventricle. J Thorac Cardiovasc Surg. 1984; 88:908-13.

\title{
Anomalous aortic origin of the right coronary artery: Embryology over genetics
}

\author{
Ajay M. Patel, MD, ${ }^{a}$ Nirmal T. Sunkara, MD, ${ }^{a}$ Raylene M. Choy, BS, RDCS, ${ }^{b}$ and Shaun P. Setty, MD, ${ }^{c}$ \\ Orange and Long Beach, Calif
}

Anomalous aortic origin of the coronary artery (AAOCA) has an incidence of $0.1 \%$ to $0.6 \%,{ }^{1-3}$ with debate over genetic and embryologic mechanisms as potential causes. We describe a unique case of anomalous aortic origin of the right coronary artery (RCA) found in 1 of a pair of identical twins.

\section{CASE REPORT}

A 24-year-old man was evaluated for resting angina at an emergency department visit. An initial 12-lead electrocardiogram showed T-wave inversion in leads II, III, and aVF. Troponin I level was $4.82 \mathrm{ng} / \mathrm{mL}$ and peaked after admission at $6.80 \mathrm{ng} / \mathrm{mL}$ (reference range, 0.00-0.09 $\mathrm{ng} / \mathrm{mL}$ ). A transthoracic echocardiogram demonstrated normal left ventricular systolic function without wall motion abnormalities. Given the patient's young age and low pretest probability for coronary artery disease, a coronary computed tomography angiogram was ordered to evaluate the patient's coronary arteries.

\footnotetext{
From the Division of Cardiology, ${ }^{\mathrm{a}}$ University of California, Irvine, Orange, Calif; Department of Pediatric Cardiology, ${ }^{\mathrm{b}}$ Miller Children's Hospital/Long Beach Memorial Hospital, Long Beach, Calif; and Department of Pediatric and Adult Congenital Cardiac Surgery, ${ }^{\mathrm{c}}$ Miller Children's Hospital/Long Beach Memorial Hospital, Long Beach, Calif.

Funded by the Helen E. Hoag Endowed Chair in Pediatric Cardiovascular Surgery. Disclosures: Authors have nothing to disclose with regard to commercial support.

Received for publication Nov 14, 2014; revisions received Dec 12, 2014; accepted for publication Dec 23, 2014; available ahead of print Jan 25, 2015.

Address for reprints: Shaun P. Setty, MD, Department of Pediatric and Adult Congenital Cardiac Surgery, Miller Children's Hospital/Long Beach Memorial Hospital, 2801 Atlantic Ave, Long Beach, CA 90806 (E-mail: SSetty@memorialcare.org). J Thorac Cardiovasc Surg 2015;149:e65-6 $0022-5223 / \$ 36.00$

Copyright (c) 2015 by The American Association for Thoracic Surgery http://dx.doi.org/10.1016/j.jtcvs.2014.12.055
}

The coronary computed tomography angiogram revealed an anomalous take-off of the RCA from the left coronary sinus with an interarterial course between the aorta and the pulmonary artery (Figure 1).

Because of the presence of symptoms alone, the patient underwent a surgical repair. The anatomy consisted of an RCA origin near the right/left aortic commissure, which was slit-like and intramural for a distance of $8 \mathrm{~mm}$ with a steep angle. The specific findings of the coronary ostia and its course were made intraoperatively, as is commonly the case. The proximal RCA was unroofed (incising and excising the intramural aortic wall), dissected off the aortoventricular groove, and translocated as a large button to the right aortic sinus, allowing the coronary artery to have a gentle curve and not be under too much tension, which would alter the coronary ostial geometry. The patient's recovery was uncomplicated, and he was discharged on postoperative day 3 . He continues to do well 5 months later on follow-up. For surveillance, his identical twin had a transthoracic echocardiogram showing normal origins of both right and left coronary arteries.

\section{DISCUSSION}

The treatment of AAOCA is in evolution with different centers differing on surgical treatment options for asymptomatic individuals. There are many surgical approaches to treat patients with different AAOCA anatomic configurations. ${ }^{3}$ The presence of myocardial ischemia is a definite indication for surgery. The workup and evaluation of an asymptomatic individual are more controversial. At the present time, our preoperative imaging studies do not consistently provide the exact ostial anatomy that allows us to make a determination on high-risk AAOCA characteristics. ${ }^{3}$ There are no formal 